\title{
GDNFOS1 knockdown decreases the invasion and viability of glioblastoma cells
}

\author{
SHIYI WANG ${ }^{1,2}$, YIHONG FAN ${ }^{2}$, YI XU ${ }^{2}, \mathrm{LU} \mathrm{ZHANG}^{2}, \mathrm{LIJUN} \mathrm{CAI}^{2}$ and BIN LV ${ }^{2}$ \\ ${ }^{1}$ Department of Gastroenterology, Ningbo Hospital of TCM Affiliated to Zhejiang Chinese Medical University, \\ Ningbo, Zhejiang 315000; ${ }^{2}$ Department of Gastroenterology, The First Affiliated Hospital of \\ Zhejiang Chinese Medical University, Hangzhou, Zhejiang 310006, P.R. China
}

Received October 22, 2018; Accepted May 10, 2019

DOI: $10.3892 / \mathrm{etm} .2019 .7670$

\begin{abstract}
Glioblastoma multiforme is the most aggressive primary brain cancer in adults. Therefore, it is important to investigate the mechanisms associated with cell viability and invasion ability of the cells in glioblastoma multiforme. The opposite strand of the glial cell line-derived neurotrophic factor (GDNF) gene is used to transcribe the cis-antisense GDNF opposite strand (GDNFOS) gene, which belongs to the long noncoding RNAs. The current study assessed the effects of GDNFOS1 overexpression and interference on GDNF expression, cell viability and invasion ability in U87 and U251 MG glioblastoma cells. Overexpression and interference were performed using constructed lentiviral vectors, including long non-coding RNA GDNFOS1 overexpression vector, pL-short hairpin RNA (shRNA)-GDNFOS1-9, pL-shRNA-GDNFOS1-49, pL-shRNA-GDNFOS1-248, pL-shRNA-GDNFOS1-9+49, pL-shRNA-GDNFOS1-9+248 and pL-shRNA-GDNFOS1-49+248. Reverse transcriptionquantitative PCR was used to determine the efficiency of interference and overexpression of GDNFOS1 in U87 and U251 MG cells. GDNF protein expression in U87 and U251 MG cells was detected using western blot analysis. In addition, cell viability was detected using a cell counting kit-8 assay at 24,48 and 72h afterGDNFOS1 overexpression orinterference. A transwell invasion assay was used to detect invasion ability. Different shRNA sequences were tested and the results revealed that a combination (pL-shRNA-GDNFOS1-49+248) was most effective in the knock-down GDNFOS1. Compared with the control group, GDNF expression in U87 MG cells was significantly increased in the GDNFOS1 overexpression group and decreased in the shRNA-GDNFOS1-248 group. U87 MG
\end{abstract}

Correspondence to: Dr Yihong Fan, Department of Gastroenterology, The First Affiliated Hospital of Zhejiang Chinese Medical University, 54 Youdian Road, Hangzhou, Zhejiang 310006, P.R. China

E-mail: yihongfansjr@163.com

Key words: U87 MG, U-251 MG, glioblastoma, glial cell line-derived neurotrophic factor, opposite strand cell viability was significantly increased in the GDNFOS1 overexpression group at 24, 48 and $72 \mathrm{~h}$ compared with the negative control group. The viability of U87 MG cells was decreased in the GDNFOS1 interference group at $72 \mathrm{~h}$ when compared with the control group. The relative invasive ability was significantly increased in the GDNFOS1 overexpression group when compared with the negative control group. The invasive ability was significantly decreased in the GDNFOS1 interference group when compared with the negative control group. Similar results were exhibited by the U251 MG cells. Overall, GDNF expression, cell viability and invasion ability of glioblastoma cells significantly increased with GDNFOS1 overexpression and decreased with GDNFOS1 interference.

\section{Introduction}

Glioblastoma multiforme is the most aggressive primary brain cancer in adults worldwide (1). Following meningioma, glioblastoma multiforme is the second most common cancer of the central nervous system, globally. Glioblastoma muliforme incidence is approximately 3/100,000 per year (1). After diagnosis, the average survival time is approximately 12-15 months and $<5 \%$ of patients survive longer than 5 years, with survival time being 3 months for patients who receive no medical treatment (2). Therefore, it is important to assess the mechanisms of cell viability and invasion ability in glioblastoma multiforme.

Glial cell line-derived neurotrophic factor (GDNF) promotes the longevity of dopamine neurons in the midbrain, spinal motor neurons, peripheral sensory neurons and noradrenergic neurons (3-6). A previous study demonstrated that GDNF regulates neuronal phenotypes, the branching of neurites and synaptic plasticity (7). The opposite strand to the GDNF gene has been revealed to be associated with the transcription of cis-antisense GDNF opposite strand (GDNFOS) gene and four exons that are located in the GDNFOS gene are spliced into various isoforms (8). GDNFOS1 and GDNFOS2 encode long noncoding (lnc) RNAs, while GDNFOS3 encodes a protein of 105 amino acids (8). GDNFOS1 has been reported to overlap with GDNF transcription, whereas GDNFOS2 does not (8). Lnc RNAs regulate the homeostasis of a variety of cell and tissue types and may affect signaling pathways and gene expression (9). Glioblastoma multiforme microglia attraction 
has been demonstrated to be mediated by GDNF (10). GDNF has also been revealed to be associated with the bone morphogenetic protein 4 (BMP4)-mediated reversal of multi-drug resistance in glioblastoma multiforme (11). The dysregulation of human GDNF and GDNFOS has been revealed to be associated with the pathogenesis of brain disease. For example, GDNFOS1 was demonstrated to regulate middle temporal gyrus in Alzheimer's disease (8). However, since the GDNFOS gene was only discovered in 2011 (8), evidence of the association between GDNFOS and a variety of cancer types is scarce and the role of GDNFOS in glioblastoma is undetermined. The effects of GDNFOS1 on GDNF expression in glioblastoma cells remain to be elucidated.

The current study aimed to assess the effects of GDNFOS1 overexpression and interference on GDNF expression, cell viability and invasion ability in U87 and U251 MG glioblastoma cells.

\section{Materials and methods}

Cells and reagents. Lipofectamine $2000^{\circledR}$, SYBR qPCR mix kit, TRIzol reagent, SuperScript III reverse transcriptase, cDNA synthesis kit and packaging mix were obtained from Invitrogen (Thermo Fisher Scientific, Inc.). EcoRI/BamHI, T4 DNA ligase and Opti-Minimum Essential Medium (Opti-MEM) were from Thermo Fisher Scientific, Inc. PBS was supplied by Sigma-Aldrich (Merck KGaA). CFX96 Touch $^{\mathrm{TM}}$ Real-Time PCR Detection system was supplied by (Bio-Rad Laboratories, Inc., and lysis buffer (cat. no. P0013), protease and phosphatase inhibitors (cat. no. P1045), enhanced chemiluminescence solution (cat. no. P0018A), polyvinylidene fluoride (PVDF) membranes (cat. no. FFP24), BCA kit (cat. no. P0012) and film (cat. no. FF057) were all supplied by Beyotime Institute of Biotechnology. Primary antibody against GDNF (cat. no. ab176564) and horse-radish peroxidase (HRP)-conjugated goat anti-rabbit secondary antibody (cat. no. ab205718) were supplied by Abcam. Transwell inserts (8- $\mu \mathrm{m}$ pore size; cat. no. 3422 ) were supplied by Corning, Inc.

Glioblastoma of unknown origin U87 (HTB-14; American Type Culture Collection) and U251 MG cells (cat.no.09063001; European Collection of Authenticated Cell Cultures) were cultured in DMEM (Thermo Fisher Scientific, Inc.) supplemented with 10\% FBS (cat. no. SH30084.3; Hyclone; GE Healthcare) at $37^{\circ} \mathrm{C}$ in a humidified atmosphere of $5 \% \mathrm{CO}_{2}$. U87 cells $\left(2 \times 10^{5}\right.$ cells/well; seeded into six-well plates) were transduced with lentiviral particles at a multiplicity of infection (MOI) of 5 (12). U251 cells ( $2 \times 10^{5}$ cells/well; seeded into six-well plates) were transduced at a MOI of 10 (13). Cells were selected with $2 \mu \mathrm{g} / \mathrm{ml}$ blasticidin (Invitrogen; Thermo Fisher Scientific, Inc.) and stable clones were subsequently generated.

Construction of recombinant plasmids. The lncRNA GDNFOS1 target sequence (600 bp; NCBI accession number, JF824130.1) was synthesized. Specific primers which included target sequences with enzyme excision sites were designed and the sequences were as follows: Forward, 5'-AAT TAAGGAAGCTAGAGCGCCGGGCTTTCC-3' and reverse, 5'-TAAACCCAAGGCGCGGGCTAGCCACAAGATTTT

TGCAC-3'. PCR was used to amplify the target sequence, which was excised with restriction enzymes NheI and AscI. Synthesized GDNFOS1 DNA was amplified via PCR using KOD plus DNA polymerase (Toyobo Life Science). The thermocycling conditions were as follows: $95^{\circ} \mathrm{C}$ for $30 \mathrm{sec}, 60^{\circ} \mathrm{C}$ for $60 \mathrm{sec}$ and $72^{\circ} \mathrm{C}$ for $60 \mathrm{sec}$ (for 30 cycles). Vector PDS159_ pL6.3-CMV-GFPa1-IRES-MCS (Novobio Scientific, Inc.) was excised with NheI and $A s c \mathrm{I}$ and the products were collected using a gel extraction kit (cat. no. AP-GX-50; Corning, Inc.) according the manufacturer's protocol. The excised target sequence and vector were ligated by T4 DNA ligase at $16^{\circ} \mathrm{C}$ for $4 \mathrm{~h}$. The product was transformed into DH5 $\alpha$-cells (Beijing Transgen Biotech Co., Ltd.). Positive clones were sequenced and used to prepare the plasmids. A lncRNA GDNFOS1 overexpression vector with cytomegalovirus promoter (Novobio Scientific, Inc.) was constructed and named pL6.3-CMV-GFPa1-IRES-GDNFOS1. In addition, according to the sequences of IncRNA GDNFOS1, three pairs of oligo sequences were designed, respectively (Table I). After annealing, double stranded DNA was inserted into the lentivirus vector PDS019_pL_shRNA_F (BsmBI enzyme excision site; Novobio Scientific, Inc.) to create the lncRNA GDNFOS1 interference vector. The sequence was confirmed via Chromas software (Chromas v2.31; Technelysium Pty Ltd.). The interference vectors were named pL-shRNA-GDNFOS1-9, pL-shRNA-GDNFOS1-49 and pL-shRNA-GDNFOS1-248. Two vectors were combined and named pL-shRNA-GDNFOS1-9+49, pL-shRNA-GDNFOS1-9+248, and pL-shRNA-GDNFOS1-49+248. A scrambled vector was also used with a sequence of 5'-TGAGACGAAGCTTCGTCT CGT-3'. The software utilized for constructing the shRNA sequences was BLOCK-iT ${ }^{\mathrm{TM}}$ RNAi Designer (Thermo Fisher Scientific, Inc.; rnaidesigner.thermofisher.com/rnaiexpress).

Lentiviral packaging. A total of $3 \mu \mathrm{g}$ recombinant lentiviral plasmid and $9 \mu \mathrm{g}$ packaging mix were added into $1.5 \mathrm{ml}$ Opti-MEM. In addition, total of $1.5 \mathrm{ml} \mathrm{Opti-MEM}$ was mixed with $36 \mu \mathrm{l}$ Lipofectamine 2000 and incubated for $5 \mathrm{~min}$ at room temperature. The diluted Lipofectamine 2000 and plasmid solution were then mixed and incubated for $5 \mathrm{~min}$ at room temperature. The mixture was added into a culture dish with 293 T cells (Novobio Scientific, Inc.) and cultured at $37^{\circ} \mathrm{C}$ for $48 \mathrm{~h}$. Cell supernatant was collected using a pasteur pipette, centrifuged $(1,500 \mathrm{xg}$ for $10 \mathrm{~min}$ at room temperature) and filtered. The virus solution was condensed using centrifugation $\left(50,000 \mathrm{x} \mathrm{g}\right.$ for $2 \mathrm{~h}$ at $\left.4^{\circ} \mathrm{C}\right)$ and re-suspended in DMEM. The blank group refers to cells that were untransfected and the negative control group refers to cells transfected with the previously mentioned scrambled vector.

Reverse transcription-quantitative PCR (RT-qPCR). RT-qPCR was used to determine the efficiency of interference and overexpression in U87 and U251 MG cells. Total RNA was extracted using TRIzol reagent following manufacturer's protocol and reverse transcription was performed using a cDNA synthesis kit. Each reaction contained $0.5 \mu \mathrm{l}$ Oligo dT primers $(0.2 \mu \mathrm{g} / \mu \mathrm{l}$; Table II) and $1 \mu \mathrm{l}$ SuperScript III reverse transcriptase $(200 \mathrm{U} / \mu \mathrm{l})$. Reverse transcription was performed at $42^{\circ} \mathrm{C}$. PCR was performed using a SYBR qPCR mix kit. PCR conditions were as follows: Initial denaturation at $95^{\circ} \mathrm{C}$ for $2 \mathrm{~min}$; 40 cycles of $95^{\circ} \mathrm{C}$ for $10 \mathrm{sec}, 60^{\circ} \mathrm{C}$ for $30 \mathrm{sec}$ and 
Table I. Oligonucleotide sequences used in vector construction.

Name

Sequences $\left(5^{\prime}-3^{\prime}\right)$

shRNA-GDNFOS1-9-F

shRNA-GDNFOS1-9-R

shRNA-GDNFOS1-49-F

shRNA-GDNFOS1-49-R

shRNA-GDNFOS1-248-F

shRNA-GDNFOS1-248-R

\begin{abstract}
CACCGCTTTCCTCGCGCCTGTCGAACGAATTCGACAGGCGCGAGGAAAGC AAAAGCTTTCCTCGCGCCTGTCGAATTCGTTCGACAGGCGCGAGGAAAGC CACCGTGTCTCGCCCTCTCGCTTCTCGAAAGAAGCGAGAGGGCGAGACAC AAAAGTGTCTCGCCCTCTCGCTTCTTTCGAGAAGCGAGAGGGCGAGACAC CACCGAGTCACGGAAGAATAGAAGACGAATCTTCTATTCTTCCGTGACTC AAAAGAGTCACGGAAGAATAGAAGATTCGTCTTCTATTCTTCCGTGACTC
\end{abstract}

shRNA, short hairpin RNA; GDNFOS1, glial cell line-derived neurotrophic factor opposite strand 1; F, forward; R, reverse.

Table II. Primers used in quantitative PCR.

\begin{tabular}{ll}
\hline Primers & \multicolumn{1}{c}{ Sequences (5'-3') } \\
\hline lncRNA GDNFOS1-F & AGTGGCGAGAAAAGGAGCTG \\
lncRNA GDNFOS1-R & GCACCTTGTGTTTGCCTGTT \\
GDNF-F & AGTGACAAAGTAGGGCAGGC \\
GDNF-R & CCACACCTTTTAGCGGAATGC \\
$\beta$-actin-F & AGGGAAATCGTGCGTGAC \\
$\beta$-actin-R & CGCTCATTGCCGATAGTG \\
\hline
\end{tabular}

Lnc, long-coding RNA; GDNF, glial cell line-derived neurotrophic factor; OS, opposite strand; F, forward; R, reverse.

$70^{\circ} \mathrm{C}$ for $45 \mathrm{sec}$. A CFX96 Touch $^{\mathrm{TM}}$ Real-Time PCR Detection system was used during PCR. Gene expression was normalized to $\beta$-actin. The $2-^{\Delta \Delta C q}$ method was used to determine qPCR results (14).

Western blot analysis. GDNF expression in U87 and U251 MG cells was detected using western blot analysis. Cells were lysed in lysis buffer with protease and phosphatase inhibitors at $4^{\circ} \mathrm{C}$ for $1 \mathrm{~h}$. The lysis mixture was centrifuged at $4^{\circ} \mathrm{C}$ at $10,000 \mathrm{x} g$ for $10 \mathrm{~min}$. Supernatant with cellular proteins was collected and used in the subsequent experiments. The protein concentration was measured using a BCA kit and proteins were separated using SDS-PAGE (10\% gel; $40 \mu \mathrm{g}$ protein/lane; $120 \mathrm{~V})$. The separated proteins were transferred to PVDF (100 V for $2 \mathrm{~h}$ ). The membranes were blocked with $5 \%$ non-fat milk at room temperature for $1 \mathrm{~h}$ and incubated with primary antibodies against GDNF (1:300) and $\beta$-actin (cat. no. ab8227; $1: 1,000$; Abcam) at $4^{\circ} \mathrm{C}$ overnight. After being washed with Tris-buffered saline with Tween-20, membranes were incubated with HRP-conjugated goat anti-rabbit secondary antibody $(1: 5,000)$ at room temperature for $1 \mathrm{~h}$. Membranes were subsequently incubated in an enhanced chemiluminescence solution at room temperature for $10 \mathrm{~min}$. Images were captured on film in a dark room. Experiments were repeated three times. Blot images were quantified in greyscale using ImageJ v1.42 (National Institutes of Health) and protein expression was presented relative to the control group. The results in control group were normalized using the mean results. However, there was some variability in control samples.
Cell viability assay. U87 MG and U251 MG cell viability was detected using a cell counting kit (CCK)-8 assay at $0,24,48$ and $72 \mathrm{~h}$ after GDNFOS1 overexpression or interference. CCK-8 reagent (Dojindo Molecular Technologies, Inc.) was added into each well of 96-well culture plates and incubated for $4 \mathrm{~h}$. A microplate reader was used to measure the absorbance at a wavelength of $490 \mathrm{~nm}$. The reading of each group was divided by the baseline reading at $0 \mathrm{~h}$ to determine relative cell viability. Experiments were repeated three times.

Transwell invasion assay. Matrigel $(1 \mathrm{~g} / \mathrm{l} ; 50 \mu \mathrm{l})$ was used to coat the membrane of the upper transwell compartment, and incubated at $37^{\circ} \mathrm{C}$ for $1 \mathrm{~h}$. The upper compartment was filled with the U87 and U251 MG cell suspension in DMEM (200 $\mu \mathrm{l}$; $2 \times 10^{5}$ cells $/ \mathrm{ml}$ ) and the lower compartment was filled with DMEM that contained $10 \%$ FBS $(800 \mu \mathrm{l})$. Cells were subsequently incubated for $24 \mathrm{~h}$ at $37^{\circ} \mathrm{C}$. The microporous membrane was then fixed with $4 \%$ paraformaldehyde at room temperature for $30 \mathrm{~min}$. Crystal violet (1\%) was used to stain the lower side of membrane at room temperature for $10 \mathrm{~min}$ and was subsequently washed with PBS twice. Cells were observed under a light microscope (magnification, $\mathrm{x} 400 ; 6$ random fields of view per group) and cells that had invaded through the membrane were counted. The average number of cells that transgressed through the membrane was divided by that in the blank group to calculate the relative cell invasion of U87 and U251 MG cells. Experiments were repeated three times.

Statistical analysis. Statistical data were analyzed using GraphPad Prism software (version 5.0; GraphPad Software, Inc.). The results are presented as the mean \pm standard error. Differences between three and more groups were compared using a one-way ANOVA followed by the Bonferroni post-hoc test. $\mathrm{P}<0.05$ was considered to indicate a statistically significant difference.

\section{Results}

Confirmation of GDNFOS1 overexpression and interference in U87andU251 MGcells.Compared with thenegativecontrolgroup, GDNFOS1 mRNA expression in U87 MG cells was increased significantly in the GDNFOS1 overexpression group $(\mathrm{P}<0.001$; Fig. 1A). In addition, GDNFOS1 mRNA expression in U87 MG cells was significantly decreased in the shRNA-GDNFOS1-248 group when compared with the negative control group $(\mathrm{P}<0.05$; 

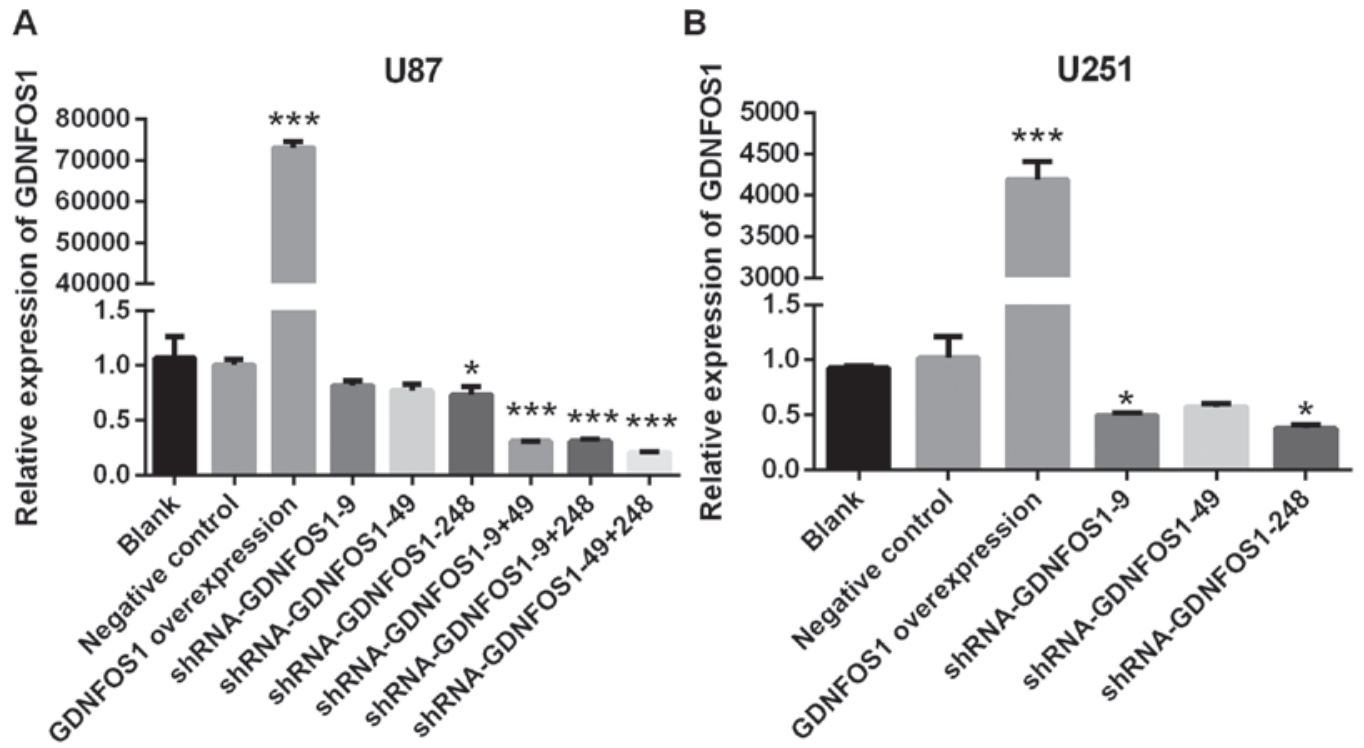

Figure 1. Confirmation of the overexpression and interference of GDNFOS1 in U87 and U251 MG cells. Reverse transcription quantitative PCR analysis of GDNFOS1 mRNA expression in (A) U87 MG cells and (B) U251 MG cells. Data are presented as the mean \pm standard deviation of three measurements per group. ${ }^{*} \mathrm{P}<0.05$ and ${ }^{* * *} \mathrm{P}<0.001$ vs. negative control group. GDNFOS1, glial cell line-derived neurotrophic factor OS1; shRNA, short hairpin RNA.

Fig. 1A). A combination of interference vectors caused higher GDNFOS1 expression inhibition in U87 MG cells. GDNFOS1 mRNA expression was significantly decreased in the shRNA-GDNFOS1-9 + shRNA-GDNFOS1-49 combination, shRNA-GDNFOS1-9 + shRNA-GDNFOS1-248 combination and shRNA-GDNFOS1-49 + shRNA-GDNFOS1-248 combination, when compared with the negative control group (all $\mathrm{P}<0.001$; Fig. 1A). The shRNA-GDNFOS1-49 + shRNA-GDNFOS1-248 combination exhibited the highest inhibition of GDNFOS1 expression in U87 MG cells. The shRNA-GDNFOS1-49 + shRNA-GDNFOS1-248 combination was therefore used in the subsequent experiments. Similarly, when compared with the negative control group, GDNFOS1 mRNA expression in U251 MG cells was significantly higher in the GDNFOS1 overexpression group $(\mathrm{P}<0.001$; Fig. $1 \mathrm{~B})$ and significantly lower in the shRNA-GDNFOS1-9 and shRNA-GDNFOS1-248 groups $(\mathrm{P}<0.05$; Fig. 1B). ShRNA-GDNFOS1-248 exhibited the highest interference ability in U251 cells and was therefore used in the subsequent experiments.

Protein expression of GDNF in U87 and U251 MG cells is significantly increased in the GDNFOS1 overexpression group and decreased in the GDNFOS1 interference group. When compared with the control group, GDNF protein expression in U87 MG cells was significantly increased in the GDNFOS1 overexpression group $(\mathrm{P}<0.05$; Fig. $2 \mathrm{~A})$ and significantly decreased in the GDNFOS1 interference group $(\mathrm{P}<0.001$; Fig. 2A). In addition, the protein expression of GDNF in U251 MG cells was significantly increased in the GDNFOS1 overexpression group $(\mathrm{P}<0.01$; Fig. $2 \mathrm{~B})$ and significantly decreased in the GDNFOS1 interference group ( $\mathrm{P}<0.05$; Fig. 2B).

Viability of U87 MG and U251 cells is significantly increased in the GDNFOS1 overexpression group and decreased in the GDNFOS1 interference group. When compared with the negative control group, U87 MG cell viability increased significantly in the GDNFOS1 overexpression group at 24, 48 and $72 \mathrm{~h}$ $(\mathrm{P}<0.01, \mathrm{P}<0.05$ and $\mathrm{P}<0.01$, respectively; Fig. 3A). Meanwhile, U87 MG cell viability decreased significantly in the GDNFOS1 interference group at $72 \mathrm{~h}$ when compared with the negative control group $(\mathrm{P}<0.001$; Fig. 3A). Furthermore, U251 MG cell viability significantly increased in the GDNFOS1 overexpression group at 24, 48 and $72 \mathrm{~h}(\mathrm{P}<0.01 ; \mathrm{P}<0.001$; $\mathrm{P}<0.001$, respectively; Fig. 3B) and significantly decreased in the GDNFOS1 interference group at 24, 48 and $72 \mathrm{~h}(\mathrm{P}<0.01$; $\mathrm{P}<0.001 ; \mathrm{P}<0.001$, respectively; Fig. 3B).

Invasion ability is significantly increased in the GDNFOS1 overexpression group and decreased in the GDNFOS1 interference group. The relative invasion ability of U87 MG cells was significantly increased in the GDNFOS1 overexpression group $(\mathrm{P}<0.01$; Fig. 4A) and significantly decreased in the GDNFOS1 interference group when compared with the negative control group ( $\mathrm{P}<0.05$; Fig. 4A). Similarly, when compared with the negative control group, the relative invasive ability of U251 MG cells was significantly increased in the GDNFOS1 overexpression group $(\mathrm{P}<0.001$; Fig. $4 \mathrm{~B})$ and significantly decreased in the GDNFOS1 interference group ( $\mathrm{P}<0.001$; Fig. 4B).

\section{Discussion}

In current study, the results demonstrated that GDNF expression, cell viability and invasion ability of glioblastoma cells significantly increased with GDNFOS1 overexpression and decreased with GDNFOS1 interference.

GDNF has previously been reported to promote the survival of peripheral motor and sensory neurons, GABAergic and cholinergic neurons in the forebrain and pancreatic $\beta$-cells (15-17). Furthermore, GDNF has been demonstrated to affect the enteric nervous system (18-24). The ability of enteric neural progenitors to develop into the enteric nervous system has been revealed to increase 
A

U87
B
U251

\section{GDNF}

\section{$\beta$-actin}

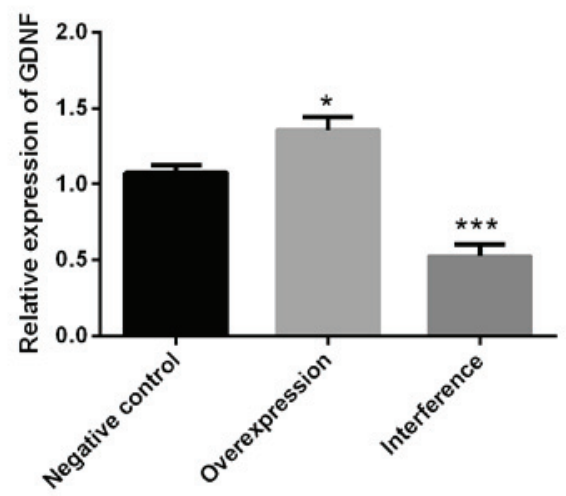

$\begin{array}{lllllllll}\mathrm{C} 1 & 01 & \mathrm{I} & \mathrm{C} 2 & \mathrm{O} 2 & \mathbf{1 2} & \mathrm{C} 3 & \mathrm{O} 3 & \mathrm{I}\end{array}$
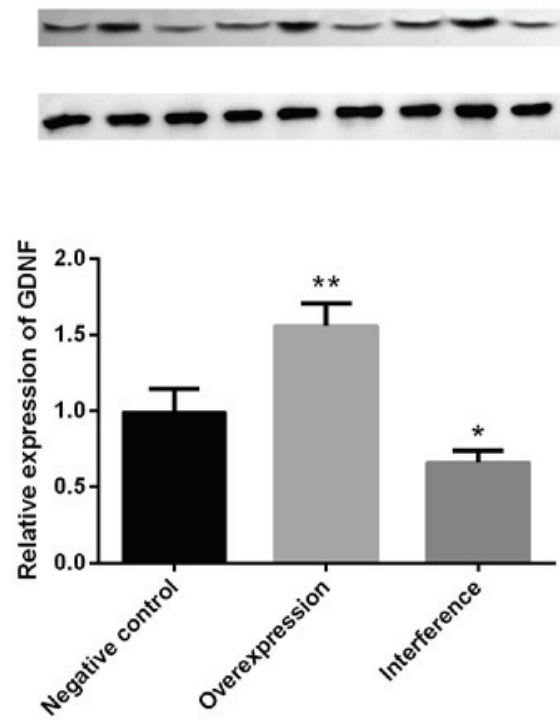

Figure 2. GDNF protein expression in U87 MG and U251 MG cells. Western blot analysis of the relative GDNF protein expression in (A) U87 MG and (B) U251 MG cells. Western blots were quantified in greyscale and relative protein expression was presented relative to the control group. A combination of shRNA-GDNFOS1-49 + shRNA-GDNFOS1-248 was used for interference in U87 cells. ShRNA-GDNFOS1-248 exhibited the highest interference ability in U251 cells and was therefore used subsequently. Experiments were performed in triplicate. Data are presented as the mean \pm standard deviation of three measurements per group. ${ }^{*} \mathrm{P}<0.05,{ }^{* *} \mathrm{P}<0.01$ and ${ }^{* * *} \mathrm{P}<0.001$ vs. the control group. The numbers $1-3$ in the western blot analysis correspond to sample numbers. C, control; O, overexpression; I, interference. GDNF, glial cell line-derived neurotrophic factor; shRNA, short hairpin RNA.

A

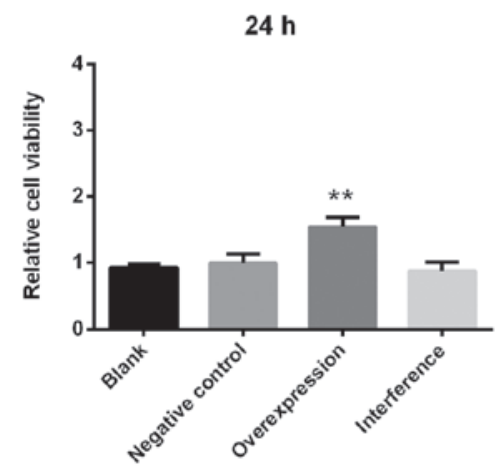

B

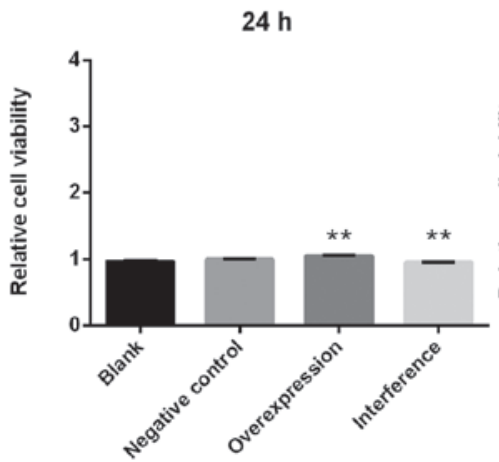

U87
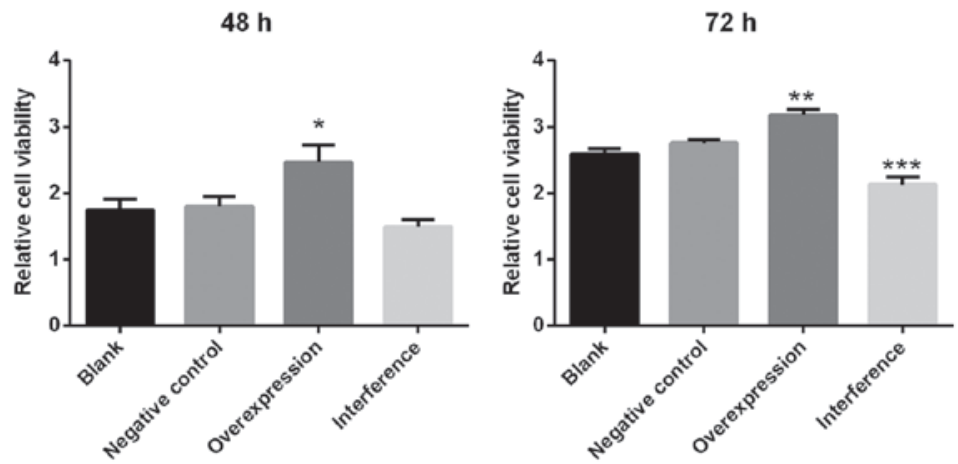

U251

$48 \mathrm{~h}$

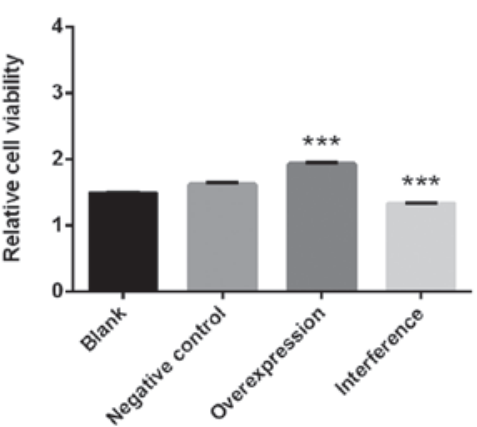

$72 \mathrm{~h}$

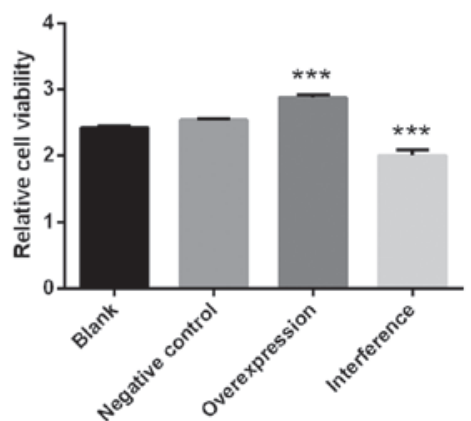

Figure 3. U87 and U251 MG cell viability. Cell counting kit-8 analysis of the relative cell viability of (A) U87 MG and (B) U251 MG cells at 24,48 and $72 \mathrm{~h}$ after glial cell line-derived neurotrophic factor opposite strand 1 overexpression or interference. Data are presented as the mean \pm standard deviation of three measurements per group. ${ }^{*} \mathrm{P}<0.05,{ }^{* *} \mathrm{P}<0.01$ and ${ }^{* * *} \mathrm{P}<0.001$ vs. the negative control group. 
A Blank

U87

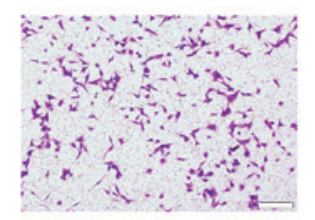

U251

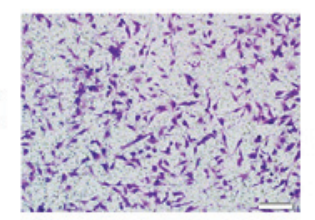

Negative Overexpression Interference control
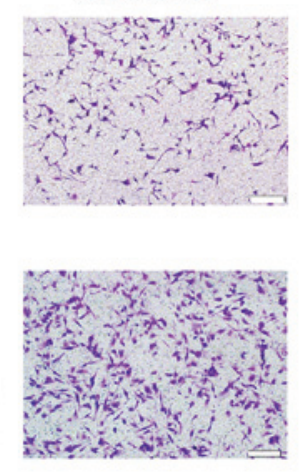
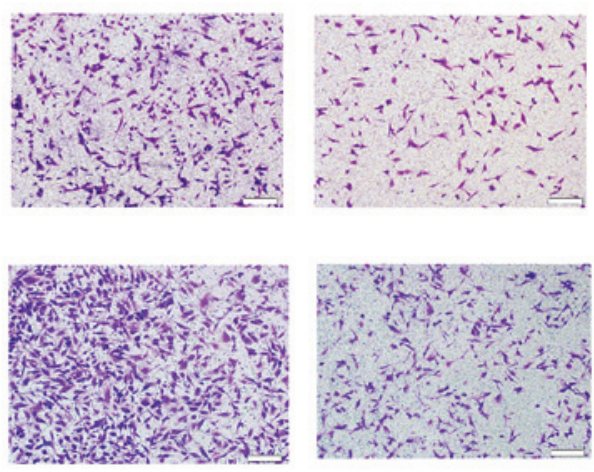

B

U87

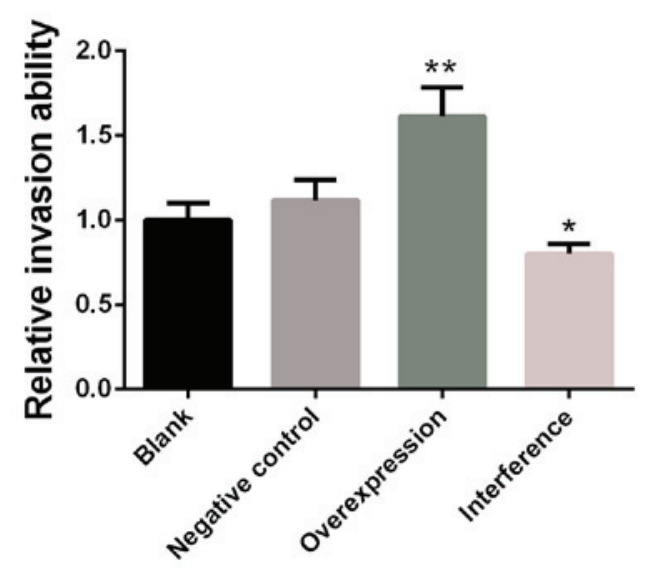

U251

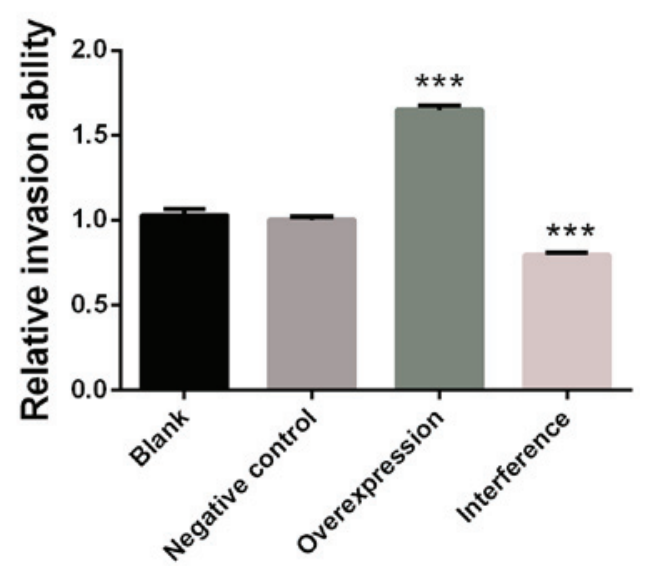

Figure 4. Transwell invasion analysis of U87 and U251 MG cells. (A) Invasion assay and (B) statistical analysis of the invasion ability of U87 and U251 MG cells. The mean number of cells that transgressed through the membrane was divided by that in the blank group to calculate relative cell invasion. Data are presented as the mean \pm standard deviation of three measurements per group. ${ }^{*} \mathrm{P}<0.05,{ }^{* *} \mathrm{P}<0.01$ and ${ }^{* * * *} \mathrm{P}<0.001$ vs. the negative control group. Scale bar, $100 \mu \mathrm{m}$.

with GDNF exposure (18-21). The loss of enteric neurons in diabetic rats has been demonstrated to be associated with decreased GDNF expression (22). In diabetic rats, the regeneration of lost enteric neurons, which is induced by high frequency electroacupuncture, has been revealed to be associated with the GDNF and PI3K/AKT signaling pathways (23). The markers of synaptic vesicles in enteric neurons were revealed to be induced by GDNF (24). In addition, GDNF has also been demonstrated to be associated with the physiology and pathophysiology of glioblastoma multiforme. Glioblastoma multiforme-induced attraction of microglia has been revealed to be mediated by GDNF (10). In a previous study, the modulation of GDNF was associated with the BMP4-mediated reversion of multi-drug resistance in glioblastoma multiforme (11). In rat C6 glioblastoma cells, the expression of GDNF has been indicated to be promoted by calcium discharge from the endoplasmic reticulum via mitogen-activated protein kinase-independent and dependent pathways (25). Fibroblast growth factor (FGF)-2 has been demonstrated to stimulate GDNF mRNA expression in rat C6 glioblastoma cells (26). After treatment with tumor necrosis factor- $\alpha$ or interleukin-1 for $24 \mathrm{~h}$, U87 MG glioblastoma cells were stimulated to release GDNF. The production of GDNF from U87 MG glioblastoma cells was also indicated to be affected by FGF-1, 2 and 9, prostaglandins $\left(\mathrm{PGA}_{2}, \mathrm{PGE}_{2}\right.$ and $\mathrm{PGI}_{2}$ ), dexamethasone and vitamin $\mathrm{D}_{3}$ (27).

GDNFOS1 belongs to the lncRNAs and the opposite strand of the GDNF gene is used to transcribe the cis-antisense GDNFOS gene (8). Unlike small noncoding RNAs including microRNAs and small interfering RNAs, long noncoding RNAs are intergenic noncoding RNAs (28). They are located between coding genes rather than antisense to them or within introns (29). Kidney, testis and ovary display the highest mRNA expression of GDNFOS1 (8). In the brain, higher expression GDNFOS1 was exhibited in the nucleus accumbens and cerebellum compared with other brain regions (8). The expression of the GDNF isoform Ex1_4L is higher than GDNFOS1 expression in the human brain (8). The first exon of GDNFOS1 has been revealed to be composed of 136 nucleotides that are reversely complementary to the 5'-untranslated region of the GDNF isoform Ex1_4L/S (30). Exon 2-short and exon 3-short are spliced from exon 1 of GDNFOS1 via intra-exonal splicing, whereas exon 4-short is spliced from exon 1 of GDNFOS1 via alternative poly-adenylation (8).

In the present study, the results revealed that GDNF expression, cell viability and invasion ability of glioblastoma cells significantly increased with GDNFOS1 overexpression and decreased with GDNFOS1 interference. Studies that assess the 
association between GDNFOS1 and glioblastoma multiforme are required. To the best of our knowledge, for the first time, the present study revealed that GDNFOS1 is associated with the regulation of viability and invasion in glioblastoma cell lines U87 and U251. The increased cell viability of glioblastoma cells observed in the present study, may be associated with increased GDNF expression due to the fact GDNFOS1 overlaps with GDNF mRNA. The molecular mechanisms underlying how GDNFOS1 regulated the expression of GDNF requires further investigation. The cross-link regulation of precursor $\mathrm{N}$-cadherin and fibroblast growth factor receptor 1 by GDNF has been demonstrated to increase the viability of U251 glioblastoma cells (31). GDNF has also been revealed to enhance the viability of human cumulus cells by downregulating miR-145-5p (32). In a previous study, GDNF reduced apoptosis in dopaminergic neurons in vitro (33) and prevented ethanol-induced apoptosis (34). In addition, GDNF has been revealed to serve an important role in the aggressive behavior and invasion of cancer. The perineural invasion of pancreatic cancer cells has been reported to be induced by the secretion of GDNF from macrophages (35). The GDNF receptor, which is released by nerves, enhanced cancer cell perineural invasion via GDNF-RET signaling (36). An antibody against the GDNF receptor was revealed to provide a targeted therapeutic opportunity for patients with breast cancer (37). In addition, GDNFOS1 may stimulate the viability and invasion ability of glioblastoma cells through other molecular mechanisms not involving GDNF. Further studies are required to elucidate the underlying biological mechanisms behind this interaction.

In the current study, the viability of glioblastoma cells when GDNFOS1 was overexpressed or interfered was detected, but this was not tested in normal cell lines. Migration ability was also not determined in the present study. In previous studies however, the changes are often the same between tumor invasion and migration in both tumor cells and tumors (38-42). Future experiments should address the limitations of the present study.

In conclusion, the current study demonstrated that GDNF expression, cell viability and invasion ability of glioblastoma cells significantly increased with GDNFOS1 overexpression and decreased with GDNFOS1 interference.

\section{Acknowledgements}

Not applicable.

\section{Funding}

The present study was supported by National Natural Science Foundation of China (grant no. 81473506; Dr Yihong Fan), Zhejiang Provincial Construction Foundation of China (grant no. WKJ-ZJ-1531; Dr Bin Lv), Zhejiang Provincial Natural Science Foundation of China (grant no. LY17H290009; Dr Yihon Fan) and Zhejiang Science and Technology Program of TCM (grant nos. 2016ZB047 and 2017ZA056; Dr Yihong Fan; and grant no. 2018ZB046; Dr Yi Xu).

\section{Availability of data and materials}

The datasets used and/or analyzed during the present study are available from the corresponding author on reasonable request.

\section{Authors' contributions}

SW and YF conceived and designed the current study. SW, YX and $\mathrm{LZ}$ performed the experiments. $\mathrm{LC}$ and $\mathrm{BL}$ analyzed the data. SW wrote the paper. All authors have read and approved the final manuscript.

\section{Ethics approval and consent to participate}

Not applicable.

\section{Patient consent for publication}

Not applicable.

\section{Competing interests}

The authors declare that they have no competing interests.

\section{References}

1. Bleeker FE, Molenaar RJ and Leenstra S: Recent advances in the molecular understanding of glioblastoma. J Neurooncol 108: 11-27, 2012

2. Gallego O: Nonsurgical treatment of recurrent glioblastoma. Curr Oncol 22: e273-e281, 2015.

3. Henderson CE, Phillips HS, Pollock RA, Davies AM, Lemeulle C, Armanini M, Simmons L, Moffet B, Vandlen RA, Simpson LC, et al: GDNF: A potent survival factor for motoneurons present in peripheral nerve and muscle. Science 266: 1062-1064, 1994.

4. Lin LF, Doherty DH, Lile JD, Bektesh S and Collins F: GDNF: A glial cell line-derived neurotrophic factor for midbrain dopaminergic neurons. Science 260: 1130-1132, 1993.

5. Arenas E, Trupp M, Akerud P and Ibáñez CF: GDNF prevents degeneration and promotes the phenotype of brain noradrenergic neurons in vivo. Neuron 15: 1465-1473, 1995.

6. Trok K, Hoffer B and Olson L: Glial cell line-derived neurotrophic factor enhances survival and growth of prenatal and postnatal spinal cord transplants. Neuroscience 71: 231-241, 1996.

7. Airaksinen MS and Saarma M: The GDNF family: Signalling, biological functions and therapeutic value. Nat Rev Neurosci 3: 383-394, 2002.

8. Airavaara M, Pletnikova O, Doyle ME, Zhang YE, Troncoso JC and Liu QR: Identification of novel GDNF isoforms and cis-antisense GDNFOS gene and their regulation in human middle temporal gyrus of Alzheimer disease. J Biol Chem 286: 45093-45102, 2011.

9. Shi C, Zhang L and Qin C: Long non-coding RNAs in brain development, synaptic biology, and Alzheimer's disease. Brain Res Bull 132: 160-169, 2017.

10. Ku MC, Wolf SA, Respondek D, Matyash V, Pohlmann A, Waiczies S, Waiczies H, Niendorf T, Synowitz M, Glass R and Kettenmann H: GDNF mediates glioblastoma-induced microglia attraction but not astrogliosis. Acta Neuropathol 125: 609-620, 2013.

11. Liu B, Chen Q, Tian D, Wu L, Dong H, Wang J, Ji B, Zhu X, Cai Q, Wang L and Zhang S: BMP4 reverses multidrug resistance through modulation of BCL-2 and GDNF in glioblastoma. Brain Res 1507: 115-124, 2013.

12. Feng SY, Dong CG, Wu WK, Wang XJ, Qiao J and Shao JF: Lentiviral expression of anti-microRNAs targeting miR-27a inhibits proliferation and invasiveness of U87 glioma cells. Mol Med Rep 6: 275-281, 2012.

13. Li G, Zhang H, Liu Y, Kong L, Guo Q and Jin F: Effect of temozolomide on livin and caspase-3 in U251 glioma stem cells. Exp Ther Med 9: 744-750, 2015.

14. Livak KJ and Schmittgen TD: Analysis of relative gene expression data using real-time quantitative PCR and the 2(-Delta Delta C(T)) method. Methods 25: 402-408, 2001.

15. Trupp M, Rydén M, Jörnvall H, Funakoshi H, Timmusk T, Arenas E and Ibáñez CF: Peripheral expression and biological activities of GDNF, a new neurotrophic factor for avian and mammalian peripheral neurons. J Cell Biol 130: 137-148, 1995. 
16. Williams LR, Inouye G, Cummins V and Pelleymounter MA Glial cell line-derived neurotrophic factor sustains axotomized basal forebrain cholinergic neurons in vivo: Dose-response comparison to nerve growth factor and brain-derived neurotrophic factor. J Pharmacol Exp Ther 277: 1140-1151, 1996.

17. Mwangi S, Anitha M, Mallikarjun C, Ding X, Hara M, Parsadanian A, Larsen CP, Thule P, Sitaraman SV, Anania F and Srinivasan S: Glial cell line-derived neurotrophic factor increases beta-cell mass and improves glucose tolerance. Gastroenterology 134: 727-737, 2008.

18. McKeown SJ, Mohsenipour M, Bergner AJ, Young HM and Stamp LA: Exposure to GDNF enhances the ability of enteric neural progenitors to generate an enteric nervous system. Stem Cell Reports 8: 476-488, 2017.

19. Worley DS, Pisano JM, Choi ED, Walus L, Hession CA, Cate RL, Sanicola M and Birren SJ: Developmental regulation of GDNF response and receptor expression in the enteric nervous system. Development 127: 4383-4393, 2000.

20. Schiltz CA, Benjamin J and Epstein ML: Expression of the GDNF receptors ret and GFRalpha1 in the developing avian enteric nervous system. J Comp Neurol 414: 193-211, 1999.

21. Chalazonitis A, Rothman TP, Chen J and Gershon MD: Age-dependent differences in the effects of GDNF and NT-3 on the development of neurons and glia from neural crest-derived precursors immunoselected from the fetal rat gut: Expression of GFRalpha-1 in vitro and in vivo. Dev Biol 204: 385-406, 1998.

22. Du F, Wang L, Qian W and Liu S: Loss of enteric neurons accompanied by decreased expression of GDNF and PI3K/Akt pathway in diabetic rats. Neurogastroenterol Motil 21: 1229-e114, 2009.

23. Du F and Liu S: Electroacupuncture with high frequency at acupoint ST-36 induces regeneration of lost enteric neurons in diabetic rats via GDNF and PI3K/AKT signal pathway. Am J Physiol Regul Integr Comp Physiol 309: R109-R118, 2015.

24. Bottner M, Harde J, Barrenschee M, Hellwig I, Vogel I, Ebsen M and Wedel T: GDNF induces synaptic vesicle markers in enteric neurons. Neurosci Res 77: 128-136, 2013.

25. Oh-hashi K, Kaneyama M, Hirata Y and Kiuchi K: ER calcium discharge stimulates GDNF gene expression through MAPK-dependent and -independent pathways in rat C6 glioblastoma cells. Neurosci Lett 405: 100-105, 2006.

26. Suter-Crazzolara $C$ and Unsicker K: GDNF mRNA levels are induced by FGF-2 in rat C6 glioblastoma cells. Brain Res Mol Brain Res 41: 175-182, 1996.

27. Verity AN, Wyatt TL, Lee W, Hajos B, Baecker PA, Eglen RM and Johnson RM: Differential regulation of glial cell line-derived neurotrophic factor (GDNF) expression in human neuroblastoma and glioblastoma cell lines. J Neurosci Res 55: 187-197, 1999.

28. Akella A, Bhattarai S and Dharap A: Long noncoding RNAs in the pathophysiology of ischemic stroke. Neuromolecular Med, 2019.

29. Bakhtiarizadeh MR and Salami SA: Identification and expression analysis of long noncoding RNAs in fat-tail of sheep breeds. G3 (Bethesda) 9: 1263-1276, 2019.

30. Zhang Y, Liu XS, Liu QR and Wei L: Genome-wide in silico identification and analysis of cis natural antisense transcripts (cis-NATs) in ten species. Nucleic Acids Res 34: 3465-3475, 2006.
31. Tang CX, Gu YX, Liu XF, Tong SY, Ayanlaja AA, Gao Y, Ji GQ, Xiong Y, Huang LY and Gao DS: Cross-link regulation of precursor N-cadherin and FGFR1 by GDNF increases U251MG cell viability. Oncol Rep 40: 443-453, 2018.

32. Cui L, Fang L, Mao X, Chang HM, Leung PCK and Ye Y: GDNF-induced downregulation of miR-145-5p enhances human oocyte maturation and cumulus cell viability. J Clin Endocrinol Metab 103: 2510-2521, 2018.

33. Clarkson ED, Zawada WM and Freed CR: GDNF reduces apoptosis in dopaminergic neurons in vitro. Neuroreport 7: 145-149, 1995.

34. McAlhany RE Jr, West JR and Miranda RC: Glial-derived neurotrophic factor (GDNF) prevents ethanol-induced apoptosis and JUN kinase phosphorylation. Brain Res Dev Brain Res 119: 209-216, 2000.

35. Cavel O, Shomron O, Shabtay A, Vital J, Trejo-Leider L, Weizman N, Krelin Y, Fong Y, Wong RJ, Amit M and Gil Z: Endoneurial macrophages induce perineural invasion of pancreatic cancer cells by secretion of GDNF and activation of RET tyrosine kinase receptor. Cancer Res 72: 5733-5743, 2012.

36. He S, Chen CH, Chernichenko N, He S, Bakst RL, Barajas F, Deborde S, Allen PJ, Vakiani E, Yu Z and Wong RJ: GFR $\alpha 1$ released by nerves enhances cancer cell perineural invasion through GDNF-RET signaling. Proc Natl Acad Sci USA 111: E2008-E2017, 2014

37. Bhakta S, Crocker LM, Chen Y, Hazen M, Schutten MM, Li D, Kuijl C, Ohri R, Zhong F, Poon KA, et al: An Anti-GDNF family receptor alpha 1 (GFRA1) antibody-drug conjugate for the treatment of hormone receptor-positive breast cancer. Mol Cancer Ther 17: 638-649, 2018.

38. Wang Y, Li Z, Zhang H, Jin H, Sun L, Dong H, Xu M, Zhao P, Zhang B, Wang J, et al: HIF- $1 \alpha$ and HIF-2 $\alpha$ correlate with migration and invasion in gastric cancer. Cancer Biol Ther 10: 376-382, 2010.

39. Gao J, Yu SR, Yuan Y, Zhang LL, Lu JW, Feng JF and Hu SN: MicroRNA-590-5p functions as a tumor suppressor in breast cancer conferring inhibitory effects on cell migration, invasion and epithelial-mesenchymal transition by downregulating the Wnt- $\beta$-catenin signaling pathway. J Cell Physiol 234: 1827-1841, 2019.

40. Wu D, Liu J, Chen J, He H, Ma H and Lv X: miR-449a suppresses tumor growth, migration and invasion in non-small cell lung cancer by targeting a HMGB1-mediated NF- $\mathrm{KB}$ signaling pathway. Oncol Res 27: 227-235, 2019.

41. Mansoori B, Mohammadi A, Ghasabi M, Shirjang S, Dehghan R, Montazeri V, Holmskov U, Kazemi T, Duijf P, Gjerstorff M and Baradaran B: miR-142-3p as tumor suppressor miRNA in the regulation of tumorigenicity, invasion and migration of human breast cancer by targeting Bach-1 expression. J Cell Physiol 234: 9816-9825, 2019.

42. Sano M, Ijichi H, Takahashi R, Miyabayashi K, Fujiwara H, Yamada T, Kato H, Nakatsuka T, Tanaka Y, Tateishi K, et al: Blocking CXCLs-CXCR2 axis in tumor-stromal interactions contributes to survival in a mouse model of pancreatic ductal adenocarcinoma through reduced cell invasion/migration and a shift of immune-inflammatory microenvironment. Oncogenesis 8: 8,2019 . 